\title{
Multidisciplinary Simulation of Graphite-Composite and Cermet Fuel Elements for NTP Point of Departure Designs
}

\author{
Mark E. M. Stewart ${ }^{1}$ \\ VPL at NASA Glenn Research Center, Cleveland, Ohio, 44135 \\ Bruce G. Schnitzler ${ }^{2}$ \\ Oak Ridge National Laboratory, Oak Ridge, Tennessee, 37831
}

\begin{abstract}
This paper compares the expected performance of two Nuclear Thermal Propul sion fuel types. High fidelity, fluid/thermal/structural + neutronic simulations help predict the performance of graphite-composite and cermet fuel types from point of departure engine designs from the Nuclear Thermal Propulsion project. Materials and nuclear reactivity issues are reviewed for each fuel type. Thermal/structural simulations predict thermal stresses in the fuel and thermal expansion mis-match stresses in the coatings. Fluid/thermal/structural/neutronic simulations provide predictions for full fuel elements. Although NTP engines will utilize many existing chemical engine components and technologies, nuclear fuel elements are a less developed engine component and introduce design uncertainty. Consequently, these fuel element simulations provide important insights into NTP engine performance.
\end{abstract}

\section{Nomenclature}

composite $=$ graphite-composite fuel is $(\mathrm{U}, \mathrm{Zr}) \mathrm{C}$-graphite (composite) fuel tested in the NF-1 reactor

$\mathrm{CTE}=$ Coefficient of Thermal Expansion, $\mathrm{m} / \mathrm{m}$

$I_{s p} \quad=$ specific impulse, $\mathrm{s}$

$M W_{t} \quad=$ megawatts of thermal energy, $\mathrm{MW}$

$T \quad=$ Temperature, $\mathrm{K}$

\section{Introduction}

$\mathrm{T}$

he promise of nuclear thermal propulsion is that its high thrust and high specific impulse - twice that of the best chemical engines - significantly reduces propellant mass as well as rocket mass, size, and cost. Nuclear Thermal Propulsion (NTP) enables short duration trips to Mars that reduce astronauts' radiation exposure. Typical round trip missions use a small fraction of the nuclear fuel's energy density; hence engine reuse is conceivable after replenishing hydrogen propellant. Yet, the major attraction of NTP is economic. When delivering payload to Low Earth Orbit (LEO) costs $\$ 5000 / \mathrm{lb}$, reducing the hydrogen propellant mass by half (conservatively 100 tons in a crewed Mars mission) saves a billion dollars of launch costs per crewed Mars mission - a substantial fraction of the cost of developing an NTP engine.

Although an NTP engine would utilize many technologies and components from chemical rocket engines (turbopumps, regeneratively cooled nozzles), the NTP fuel element is a novel component, and consequently, it is the focus of design and fabrication efforts. Chemical rockets achieve a high propellant temperature with chemical combustion in the gas. With NTP, fission heat is deposited in the solid fuel and must be transferred to the gaseous propellant through coolant channels in the fuel; this solid fuel must remain intact and not melt, even as the design goal is the highest possible fuel temperature. Consequently, the fuel is designed to thermal, structural, and neutronic limits with margins.

\footnotetext{
${ }^{1}$ Senior Research Engineer, 21000 Brookpark Road, MS VPL-3, AIAA Member.

${ }^{2}$ Post Office Box 2274, Idaho Falls, ID 83403, AIAA Senior Member.
} 
NASA's Nuclear Thermal Propulsion program has been recapturing NTP fuel element fabrication techniques and design knowledge. Engine and material research has identified two fuel types: graphite-composite and cermet. For each fuel type, there is a point of departure engine design. The graphite-composite fuel is the $(\mathrm{U}, \mathrm{Zr}) \mathrm{C}$-graphite (composite) fuel [1] from the Small Nuclear Rocket Engine (SNRE) design, late in the Rover program. The second fuel type is a ceramic-metallic (cermet) composite fuel with uranium-dioxide particles in a tungsten matrix. The fuel is $\mathrm{W}-60 \% \mathrm{UO}_{2}-6 \% \mathrm{Gd}_{2} \mathrm{O}_{3}$ fuel with a W/25\% Re cladding. The point-of-departure fuel element geometry is a variation of the General Electric (GE) 710 engine's fuel element [2], denoted GE 711. NASA has decided that graphite-composite fuel is a "leader fuel", while cermet is a "follower fuel".

The Rover/NERVA (Nuclear Engine for Rocket Vehicle Applications) program (1955-1972) was a large, "Space Race" era effort to develop a nuclear rocket, and it has become synonymous with graphite-based fuels. In the Rover/NERVA program, graphite-based reactors were designed, built, and tested in the KIWI, NRX, PHOEBUS, PEWEE, and NF thermal spectrum reactors. This series of 23 reactors advanced graphite-based NTP fuels to the point where the NRX-XE rocket reactor performed 28 burns with about 2 hours of full power operation. References [3] [4] provide a comprehensive technical history of the Rover/NERVA program.

Also in the 1960's, extensive cermet fuel sample development and testing took place at several Department of Energy, NASA, and corporate laboratories. This materials development culminated in several cermet NTP reactor designs. Argonne National Laboratory (ANL) designed two rocket reactors based on cermet fuel. The ANL200 [5] and ANL2000 were $200 \mathrm{MW}_{\mathrm{t}}$ and $2000 \mathrm{MW}_{\mathrm{t}}$ fast spectrum propulsion reactors. The performance goals of this rocket/reactor were a maximum fuel temperature of at least $2500^{\circ} \mathrm{C}(2770 \mathrm{~K})\left(I_{s p}=821\right.$ to $\left.832 \mathrm{~s}\right)$, ten hours of operation with at least 25 thermal cycles, and a fuel loss target of less than $1 \%$. The program advanced to the point where many fuel samples and several fuel elements were tested in high temperature hydrogen. NASA's Lewis Research Center (LeRC) performed extensive fuel and reactor development work and designed the thermal spectrum Tungsten Water Moderated Rocket (TWMR) [6] to similar performance goals. General Electric (GE) had a program [2] for cermet materials development and fabrication plus reactor design.

Why were cermet fuel elements not tested as a rocket/reactor, while graphite-based fuels were? Rom [7] claims that, "The potential for tungsten reactors needed intensive experimental investigation for verification. Aside from its use as a light bulb filament, very little was known about the properties of tungsten. There was essentially no data base." In contrast, there was experience with graphite in high temperature industrial applications, reactor grade graphite was available and could be fabricated with precision.

This paper compares the expected performance of graphite-based and cermet fuel elements as part of the Nuclear Thermal Propulsion program. A heterogeneous set of issues are relevant to fuel element performance. The following sections try to organize fuel geometry and compositions, materials issues, nuclear reactivity, stress, and fluid/thermal/structural simulations into a coherent narrative of expected performance of the two fuel elements.

\section{Fuel Geometry, Fuel Composition, and Fabrication}

At the beginning of the Rover/NERVA program, scientists sought materials with high strength at high temperatures. In particular, they sought high melting point materials with low vaporization rates, chemical stability, and structural strength. These nuclear reactor materials needed to be combined with fissile uranium, and low neutron absorption was also important.

An existing reactor material, graphite has a high melting (sublimation) temperature of $3915 \mathrm{~K}$; further, several carbides melt above $4100 \mathrm{~K}$, and uranium carbide melts at $2835 \mathrm{~K}$. Tungsten is another promising fuel matrix material with a melting point of $3680 \mathrm{~K}$ and the lowest vaporization rate of all materials.

How are these materials developed into a fuel composition, with a fuel element geometry that can be fabricated - all within a consistent fuel element and reactor design?

Fuel element geometry is dominated by thermal considerations: nuclear heat deposited in the fuel must be moved to the coolant channels and removed by the propellant/coolant. Figure 1 compares graphite-composite and cermet fuel geometries to scale, and one can imagine how web-thickness (coolant channel separation) is kept low to remove heat. The SNRE design includes a tie tube (concentric circular structure in Figure 1, right) with three functions: it is the structural support for the surrounding fuel elements and reactor core, it contains moderator, and it absorbs and transfers heat to a hydrogen flow to drive the turbopump - all while being maintained at cryogenic temperatures while inside a reactor. 

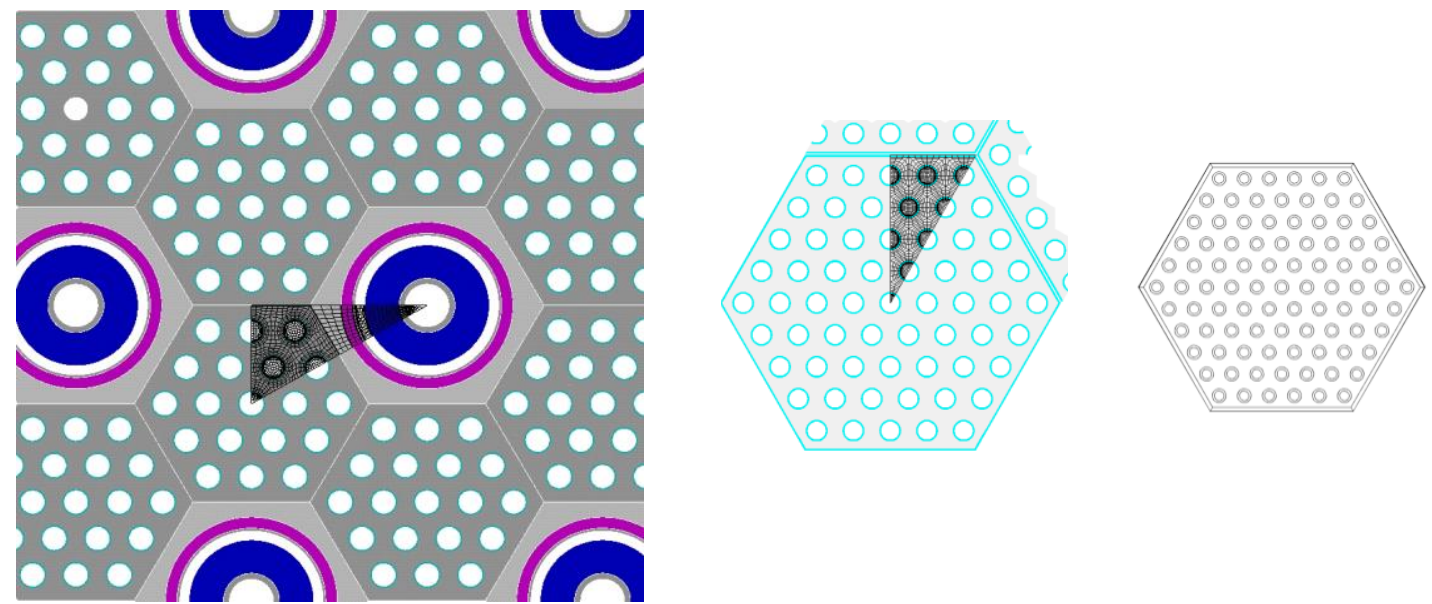

Figure 1. Cross-sectional geometries for NERVA graphite-composite (left), ANL 200 cermet (center), and GE 711 (right) fuel elements, to scale. The graphite-composite reactor includes tie tubes (concentric rings). The black spider webs are grids of symmetric sectors of the reactor core used in fluid/thermal/structural simulations. Hexagonal prism fuel elements fit together to form the reactor core as in the figure at left.

NERVA graphite-based fuels went through several geometries and compositions including plates and carbon coated $\mathrm{UC}_{2}$ spheres in graphite. In the last fuel design [1], denoted $(\mathrm{U}, \mathrm{Zr}) \mathrm{C}$-graphite (composite) fuel, the zirconium carbide $(\mathrm{ZrC})$ coating transitioned into a fuel of $\mathrm{ZrC}$ with uranium carbide (in solid solution - not particles). The $\mathrm{ZrC}$ forms an interconnected matrix even if the carbon is leached away. To build the NERVA reactors, thousands of graphite-based fuel elements (all fuel designs) were fabricated. Graphite flour, $\mathrm{ZrC}$, and $\mathrm{UO}_{2}$ powders were mixed with binders and extruded into a near-final shape (Figure 2). After curing, heat treatments and machining, a ZrC coating was applied to the coolant channels and external surface with Chemical Vapor Deposition (CVD) techniques.

Cermet fuels similarly were tested in different geometries and compositions. In the 1960's, the fuel element geometry evolved to a larger cross section with more, smaller coolant channels (Figure 1). The cermet fuel is a composite with particles of $\mathrm{UO}_{2}$ nuclear fuel contained in a tungsten (or alloy) matrix, as shown in Figure 3 . On the coolant channel and exterior surfaces, a coating of tungsten (or alloy) is applied. Fabrication involves powder metallurgical techniques where particles and powders are compacted at high pressures and temperatures. Hot Isostatic Pressing (HIP) and Spark Plasma Sintering (SPS) are typical methods. The cermet composition considered here is $\mathrm{W}-60 \% \mathrm{UO}_{2}-6 \% \mathrm{Gd}_{2} \mathrm{O}_{3}$.

\section{Materials Issues for Graphite-Based and Cermet Fuels}

This section considers some of the materials issues that are significant to fuel element design. In particular, we outline the role of fuel coating/cladding, CTE mismatch, melting temperatures, and high temperature stability.

\section{A. Materials Issues for Graphite-Based Fuels}

Graphite-based NTP fuels have two significant issues: fuel element coating is required, and the CTE mismatch between this coating and the fuel leads to coating cracking including mid-passage erosion. An important reference is Lyon [1].

First, like cermet fuels, fuel coating is essential to graphite-based fuels. Graphite forms gaseous methane and erodes when exposed to flowing, high temperature hydrogen. Although several carbide coatings were used in NERVA fuel elements, $\mathrm{ZrC}$ was used in the final designs. The coating reduces erosion by orders of magnitude, yet, on the very highest temperature surfaces, carbon diffuses
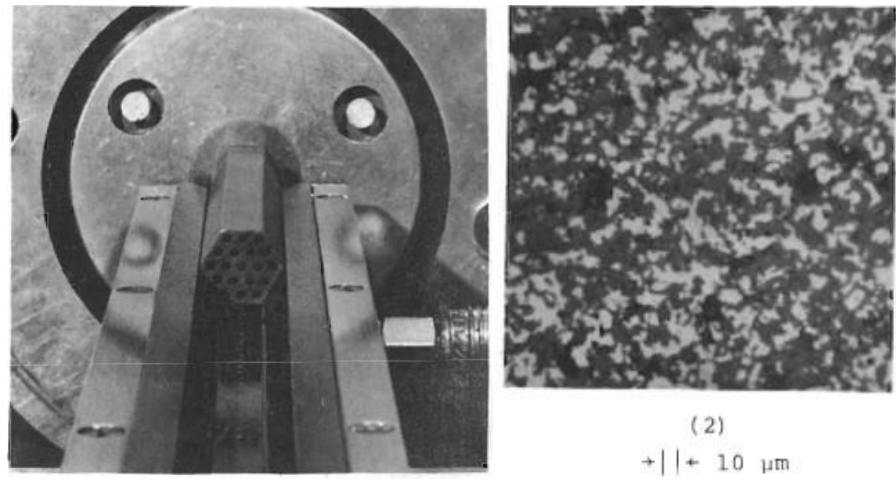

Figure 2. Extrusion of NERVA composite fuel element (left), and micrograph of the resulting heat treated $(3050 \mathrm{~K})$ fuel (right). White areas are carbide, gray are graphite, black are void. From Ref. [1]. through the coating, leading to limited fuel erosion. The surface vaporization rate of $\mathrm{ZrC}$ is $>10 \mathrm{mil} / \mathrm{hr}$ at $2800 \mathrm{~K}$. 
Second, with a CTE mismatch between the graphite-based fuel and the coating, large stresses occur at certain temperatures. While coatings are stress-free at CVD fabrication temperatures $(1500 \mathrm{~K})$, on cooling, the coating goes into tension, and some cracking occurs-particularly with larger CTE mismatches. At high temperatures, the coating is in compression. To decrease CTE mismatch, the best fuel design incorporated significant $\mathrm{ZrC}$ in the fuel matrix, that is, the $\mathrm{ZrC}$ coating transitioned into a fuel of $\mathrm{ZrC}$ with uranium carbide, all in solid solution. Multilayer coatings are being pursued that incorporate hydrogen diffusion barriers and grade the CTE mismatch to reduce peak stresses.

Graphite-composite fuel is chemically stable at high temperatures, but does eventually melt as shown in Figure 4 , left. Depending on uranium loading, the fuel is solid up to $\sim 3000 \mathrm{~K}$ when a liquid component begins to form; above $3150 \mathrm{~K}$, complete melting occurs. The $\mathrm{ZrC}$ coating melts at $3805 \mathrm{~K}$.

\section{B. Materials Issues for Cermet Fuels}

Despite the promise of tungsten's high melting point and low vaporization rate, two significant issues with the uranium dioxide fuel impeded cermet development: the high vaporization rate of $\mathrm{UO}_{2}$ above $2000 \mathrm{~K}$, and its high temperature chemical stability. Both issues were identified early in cermet fuel development, but they paced development. Cermet materials issues have been reviewed [8] [9].

The vaporization rate of uranium dioxide can be reduced by an order of magnitude by cladding the fuel element with W, or W-Re. Without cladding, the tungsten matrix alone does not sufficiently encapsulate the uranium dioxide fuel particles and limit vaporization.

Further, the high temperature chemical stability of uranium dioxide was noted in 1960, when Anderson et al [10] reported that uranium dioxide decomposes (or reduces) at high temperature and becomes hypo-stoichiometric in oxygen, $\mathrm{UO}_{2} \rightarrow \mathrm{UO}_{2-\mathrm{x}}+(\mathrm{O})$, Figure 4 , right. This instability leads to hydrogen embrittlement and fuel breakdown at high temperatures. In particular, with cooling, the

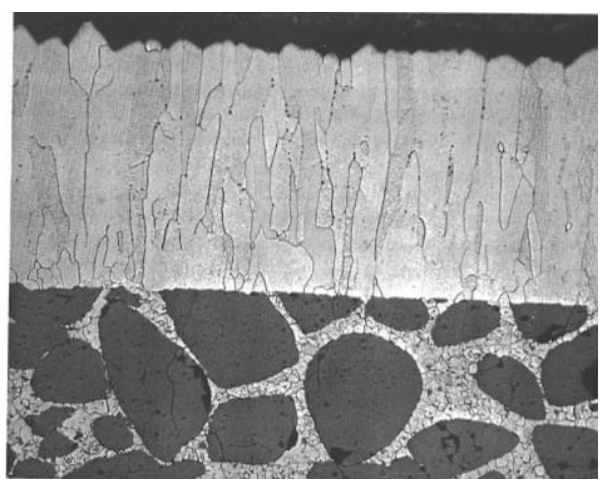

Figure 3. Cermet fuel cross section showing $\mathrm{UO}_{2}$ fuel pellets (dark) in tungsten matrix. Vapor deposited tungsten coating at top. Magnification 200X. From Ref. [20]. reaction reverses, but if oxygen has left the vicinity, free uranium forms. Oxygen diffuses out through the surfaces and grain boundaries and hydrogen diffuses in. With hydrogen present, free uranium forms uranium hydride, $\mathrm{UH}_{3}$, below $770 \mathrm{~K}$; in this example of hydrogen embrittlement the large uranium hydride molecule forces apart grain boundaries - in some cases explosively. Thermal cycling and flowing hydrogen all accelerate the decomposition of the fuel. Fuel performance is enhanced with oxygen impermeable claddings, plus stabilizers $\left(\mathrm{Gd}_{2} \mathrm{O}_{3}, \mathrm{Y}_{2} \mathrm{O}_{3}\right)$ interfere with this reduction. High temperature stabilization of $\mathrm{UO}_{2}$ is explored experimentally by Beals et al [11]. Baker et al [12] carefully explained this basic behavior, and Stewart [13] reviewed the historical development of cermets.

Figure 5 shows the best results achieved in cermet fuel testing, which were enabled by both cladding and stabilizers. Duplicated by two labs, the results show the fuel can be thermally cycled many times up to a peak temperature of $2770 \mathrm{~K}$. Surviving many thermal cycles allows engine reuse for multiple missions with hydrogen propellant reloading. However, at slightly higher temperatures, fuel degradation accelerates. The hottest $300 \mathrm{~K}$ of a cermet fuel element is shown in Figure 5, right. Figure 4 suggests that graphite-composite fuel peak temperatures will be 100 to $200 \mathrm{~K}$

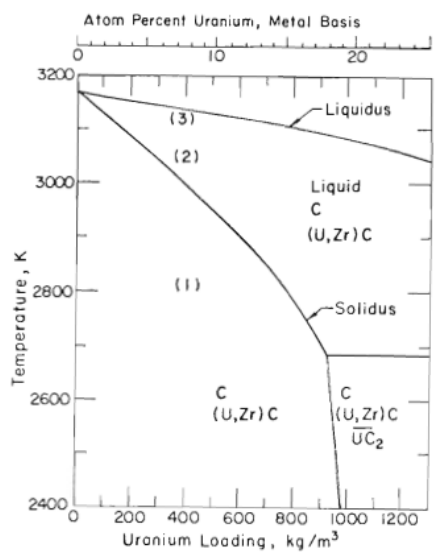

Figure 4. Pseudobinary phase diagram (left) for U-Zr-C system for graphite-composite elements from Ref. [1], and phase diagram for oxygen urani um system (right) for cermet fuels from Ref. [27]. higher than cermet temperatures.

4

American Institute of Aeronautics and Astronautics 

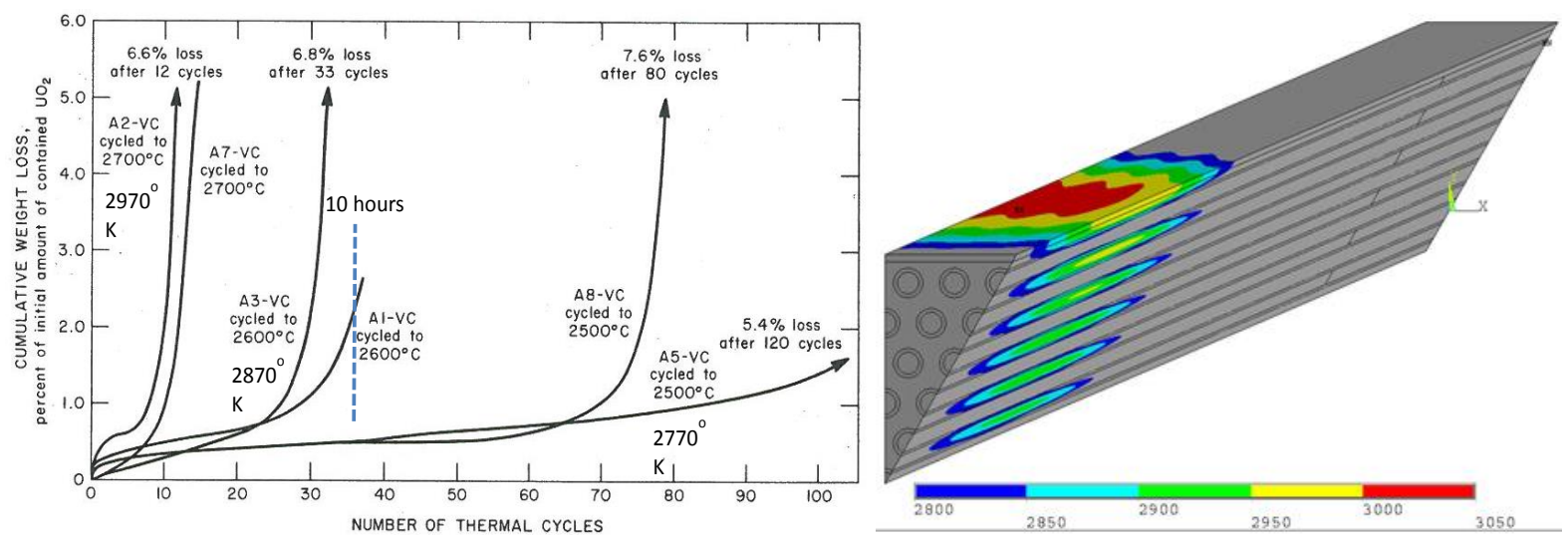

Figure 5. Fuel loss for six cermet fuel samples at three temperatures [20, p. 105] (left), and (right) the hottest $300 \mathrm{~K}$ of a cermet fuel element where this fuel decomposition likely occurs.

\section{Reactor and Reactivity Issues for Graphite-Based and Cermet Fuels}

NERVA graphite-based rocket/reactors are thermal spectrum nuclear reactors. For cermet fuel, the ANL200 [5] and GE 710 reactor designs are fast spectrum; however, the Tungsten Water Moderated Reactor (TWMR) [6] design used cermet fuel in a thermal spectrum reactor. In NTP reactor analysis, nuclear criticality has been demonstrated through MCNP (Monte Carlo N-Particle) simulations [14] for a range of engine thrust sizes for graphite-based and cermet fuels. One distinguishing feature is that cermet fast spectrum reactors require significantly more highly enriched uranium - a factor of almost ten.

Submersion criticality also distinguishes the two fuel types. If a launch accident submerged an NTP engine in water, and water penetrated into the coolant channels of the reactor core, the water's hydrogen would provide additional moderation in a thermal spectrum reaction and push the reactor toward criticality. Although neutron moderation would also be provided in a fast spectrum reactor, the reactor is more likely to be pushed away from criticality due to higher neutron absorption at the lower (more thermalized) neutron energies. A launch accident resulting in immersion in sand would tend to push either a thermal spectrum or a fast spectrum reactor core in the direction of criticality. Space nuclear treaties prohibit intentionally achieving criticality during launch and prohibit designs allowing reactor criticality during launch accidents. Graphite-based fuel reactors would need additional safeguards. During the NERVA program, submersion criticality mitigation strategies were extensively studied. Options included removable neutron absorbing wires within the fuel element coolant channels, and reactor disassembly using explosive charges

Stability during reactor startup may also distinguish the two fuel types. Again, in thermal spectrum reactors, hydrogen's moderating capability is important and differs significantly between hydrogen liquid and vapor phasesa factor of 100 in density is possible. During reactor startup, liquid hydrogen (LH2) flows into the empty flow passages of the engine (possibly warm), and it boils to chill-down some engine components. Both liquid and vapor phase hydrogen are present and boiling for a length of time until stable thermal conditions are achieved. Fuel element coolant channels are $80 \%$ of the $\mathrm{H}_{2}$ volume in an SNRE reactor core, and $19 \%$ of the reactor core volume. Liquid hydrogen is undesirable in these coolant tubes since cryogenic temperatures tend to crack coatings. However, tie tube passages - the remaining $20 \%$ of $\mathrm{H}_{2}$ volume or 5\% of the SNRE reactor core volume-would chill-down to operate at cryogenic temperatures and eventually be filled with LH2. If, during startup/chill-down, a vapor ullage was expelled from the tie tubes while the reactor was critical, the low density vapor would be replaced with LH2. This denser liquid hydrogen would increase reactivity, and the reactor control system must be able to compensate quickly enough. During the NERVA program, hydrogen reactivity insertion was a concern and investigated, yet many engine startups were performed routinely. The design objective is to ensure the tie tube passages are completely filled with dense liquid hydrogen before the reactor reaches criticality, and early, pulsed LH2 flow to the tie tubes might achieve this.

\section{Thermal/Structural Behavior of Fuel Elements}

So far, this paper has examined how materials and reactivity issues are important in designing NTP fuels - and in comparing the two potential fuels. In this section, we consider the two important stresses in NTP fuel elements: thermal stresses and CTE mismatch stresses. Further, we quantify the limitations imposed by these stresses as the fuel is pushed to its thermal and structural limits. The first two sections consider elastic stress analysis (temperature 
dependent), and the final section considers the temperature dependence of material properties, including plasticity and ductile-to-brittle transition.

\section{A. Thermal Stresses in the Fuel}

Thermal stresses limit the nuclear heat deposition into the fuel. They result when heat deposited by nuclear fission is moved to the coolant tube surface where it is removed by the coolant/propellant. This movement of heat requires a temperature gradient. Figure 6 (left) shows channel surface cooler than extremities, and these varying temperatures and varying thermal expansions induce stresses: cooler regions are in tension while hotter regions are in compression. Figure 6 (left) shows predictions of the temperature distribution through a cross section, and on the right, the predicted maximum temperature difference for a range of heat deposition rates. The thermal conductivity of graphite-based and cermet fuels are similar, and the differences in Figure 6 (right) are partially attributable to
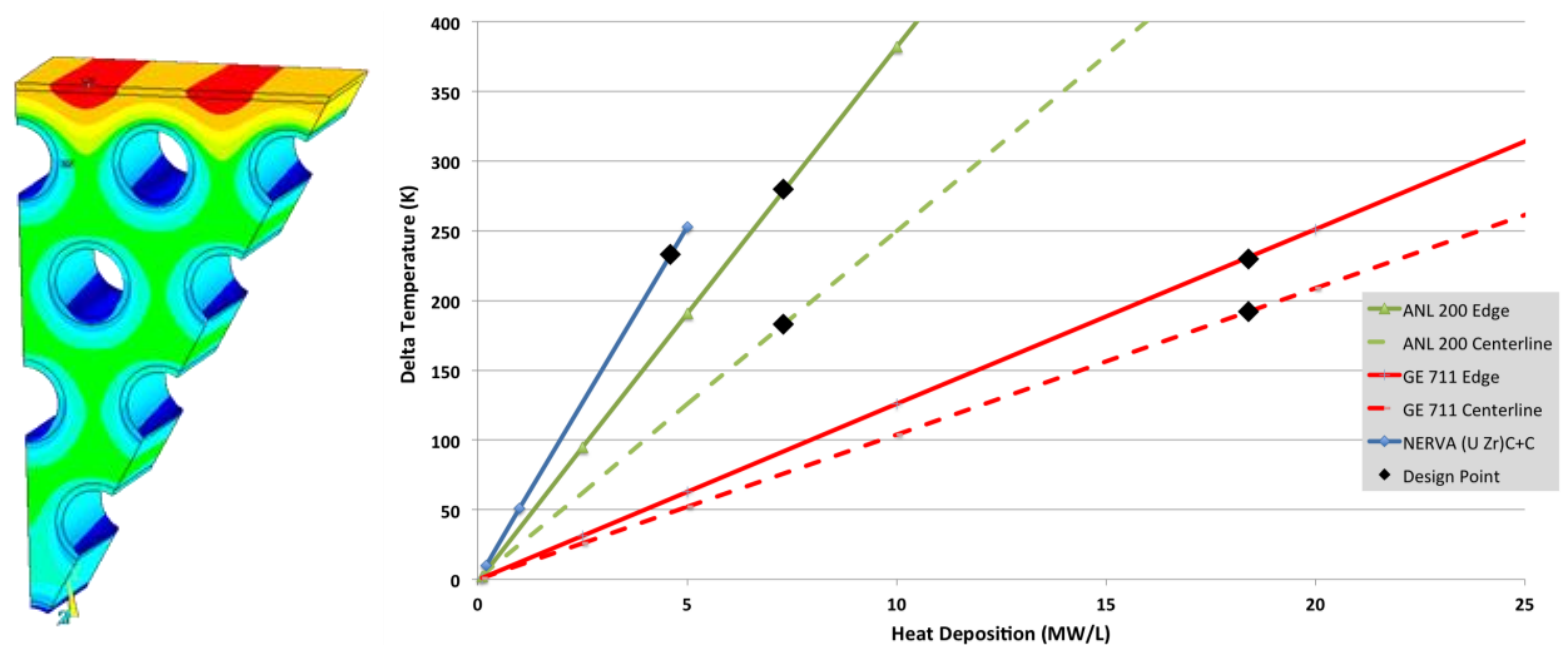

Figure 6. Temperature distribution through a GE711 fuel element cross section (left) and temperature difference through fuel element cross sections with varying heat deposition rate (right). At left, peak temperatures are on the external surface, with lesser peaks at the centerlines between coolant tubes. The temperature difference with the external surface (solid line) is greater than with the centerline (dashed line). Calculations performed with ANSYS thermal/structural [19].

differences in geometry, including web thickness.

Although temperature differences are similar between the fuels, limiting stresses are not similar due to differences in modulus of elasticity, yield and fracture strength. Graphite-composite fuel has a tensile fracture strength of $\sim 50 \mathrm{MPa}$ below $2000 \mathrm{~K}$; above $2000 \mathrm{~K}$ the fuel undergoes plastic deformation without fracture. Lyon [1] gives fracture/deformation data for graphite-composite fuel. This $50 \mathrm{MPa}$ fracture strength limits the peak heat deposition rate into the fuel to $5 \mathrm{MW}_{\mathrm{t}} / \mathrm{L}$, as shown in Figure 7. Simulations [15] used 4.6 $\mathrm{MW}_{\mathrm{t}} / \mathrm{L}$.
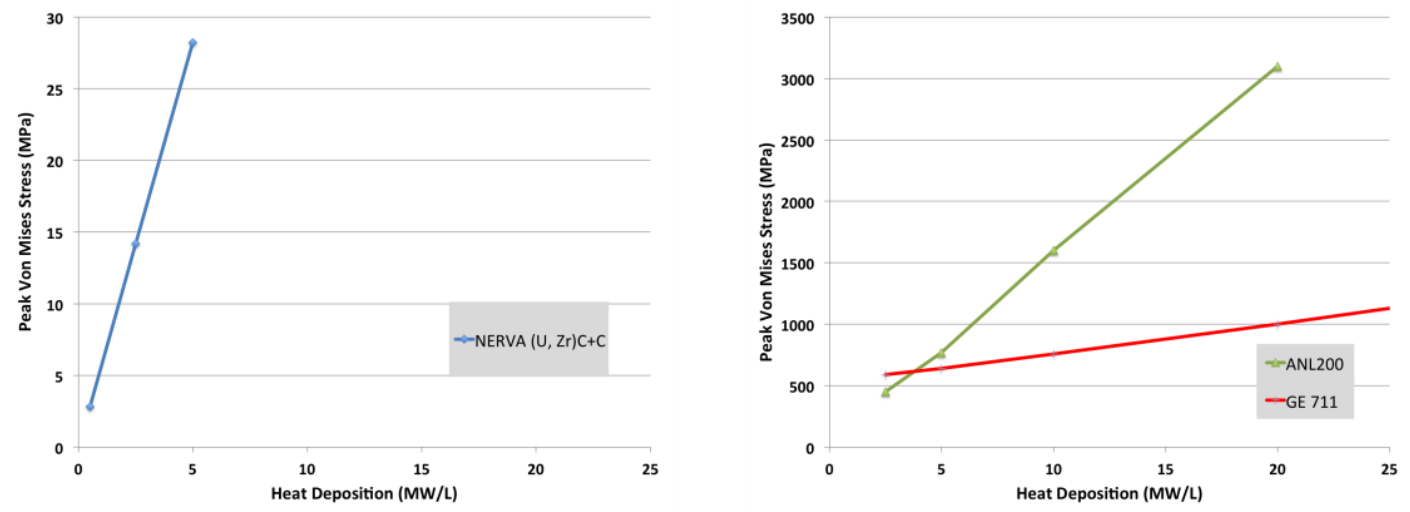

Figure 7. Elastic anal ysis of thermal stress in graphite-composite fuel at $2000 \mathrm{~K}$ with heat deposition rate (left) and in ANL 200 and GE 711 cermet fuels (right). Note the different vertical scales.

American Institute of Aeronautics and Astronautics 
Based on measured W and W-Re mechanical properties [16] [17], the yield strength of cermet fuel is an order of magnitude higher, depending on temperature. Cermet fuel reactors can operate at higher peak heat deposition rates; the ANL 200 simulations [18] used 7.3 $\mathrm{MW}_{\mathrm{t}} / \mathrm{L}$ while the GE 710 and 711 fuel element simulations used 18.4 $\mathrm{MW}_{\mathrm{t}} / \mathrm{L}$.

These stress predictions are from ANSYS thermal/structural simulations [19] using NERVA composite fuel temperature dependent property data [1] [15] (thermal conductivity, coefficient of thermal expansion (CTE), Modulus of Elasticity, and Poisson's ratio) and best estimates of cermet property data [18]. The gridded geometry is a short axial length of a symmetric sector (Figure 1) of each fuel element.

\section{B. Stresses in Fuel Element Coatings: CTE Mismatch}

As temperatures increase, different materials thermally expand by different amounts (Figure 8, left); where they are bonded - as in a coating - stresses are necessary to maintain equal expansion on both sides of the bond. The stresses in both materials oppose each other; one side is in compression, the other in tension.
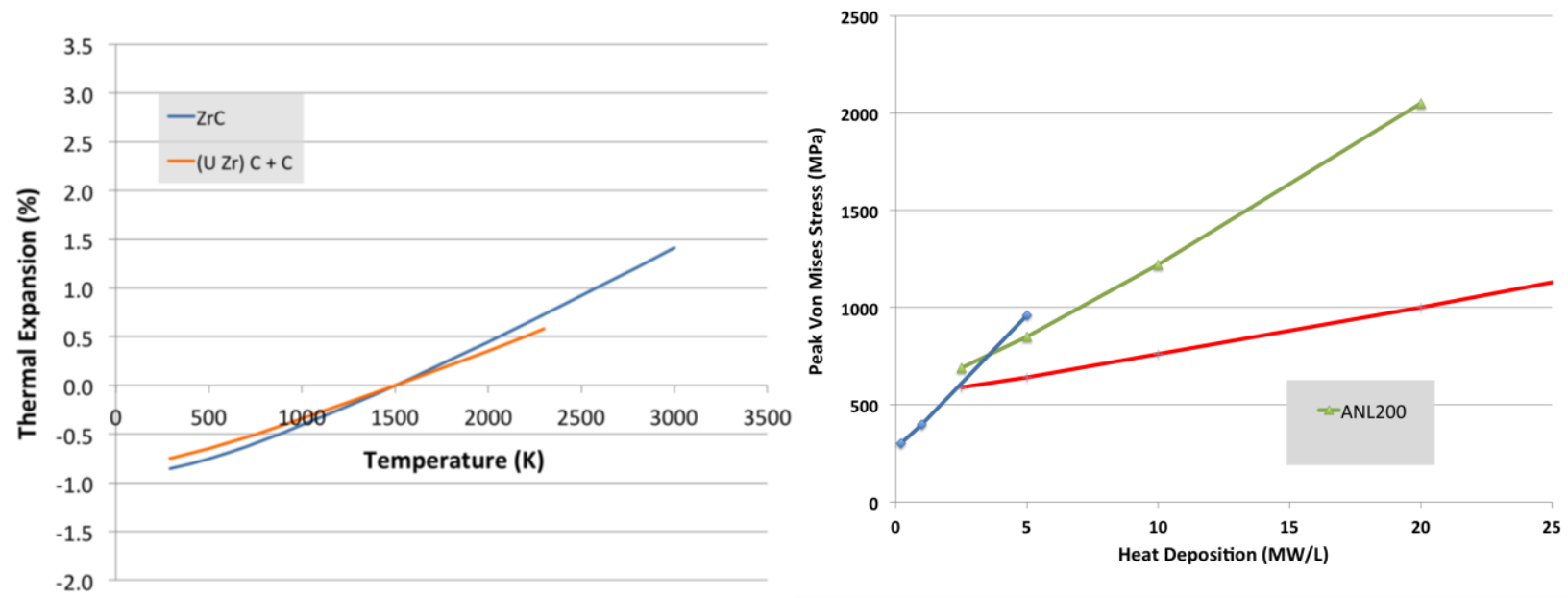

Figure 8. Comparison of thermal expansion for graphite-composite fuel (left) and predicted peak Von Mises stress (right) in the coatings of graphite-composite and cermet fuel elements. $1500 \mathrm{~K}$ is chosen here as the zero stress condition, and the thermal expansion curves cross.

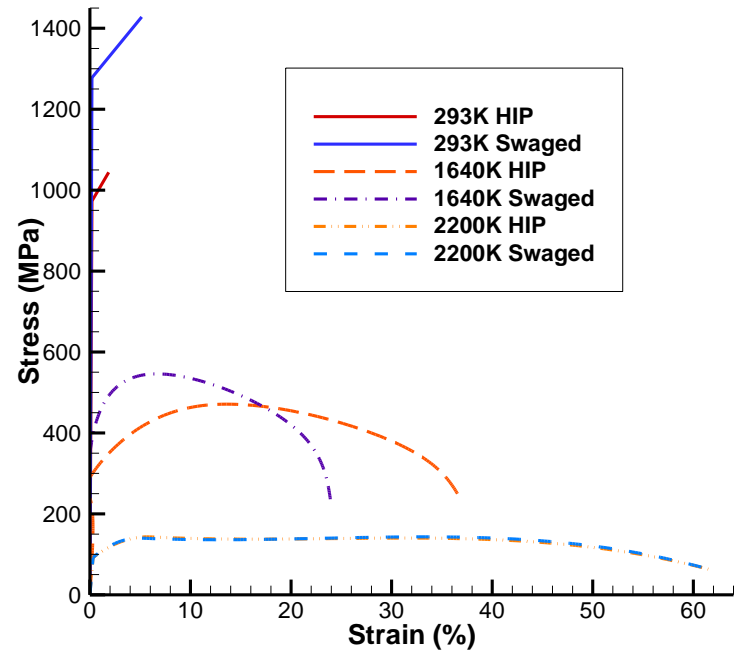

Figure 9. Stress strain curves demonstrate ductile to brittle transition for $\mathrm{W} / 25 \% \mathrm{Re}$ in tension. Data from Refs. [16] and [17]. These data are elastic-plastic input for simulations.
Interestingly, coatings for cermet and graphite fuel elements have opposite CTE mismatch stresses: the ZrC coating of $(\mathrm{U}, \mathrm{Zr}) \mathrm{C}$-graphite fuel elements is in tension on cool down, while the $\mathrm{W} / 25 \%$ Re cladding of ANL 200 fuel elements is in compression. On cool down, the $\mathrm{ZrC}$ coating of graphite-composite fuels are prone to cracking [1], while the $\mathrm{W} / 25 \% \mathrm{Re}$ cladding is prone to buckling, and this may explains the blistering found on some cermet fuel elements [20].

Figure 8, right, gives elastic predictions of CTE mismatch stresses in the coatings of graphite-composite and cermet fuels. Stress measurements for $\mathrm{ZrC}$ [21] [22] indicate these stresses levels are near fracture.

\section{Beyond Linear Stress Models: Extreme Design, Plasticity, Ductile-To-Brittle Transition}

The elastic stress analysis of the previous two sections is insightful, but mechanical properties change dramatically at higher temperatures. Fuel element materials will plastically deform, creep, and thermal cycling will reverse and cycle these deformations.

Figure 9 demonstrates the dramatic changes in mechanical properties as temperatures increase. At room temperature, $\mathrm{W} / 25 \% \mathrm{Re}$ is very hard, and it will deform 
and fracture only at high stresses. At elevated temperatures, it does not fracture, instead it deforms remarkably at lower stress levels. This plastic deformation is not reversible.

Many NTP reactor materials demonstrate similar behavior, that is, above a certain temperature, plasticity appears and high stresses yield substantial deformation; fracture is delayed or replaced by deformation. In metals, this behavior is a ductile to brittle transition. Zirconium carbide is brittle and shatters at room temperature, while above 1400-1500 K, crack propagation is impeded [22] [23]. When below $2000 \mathrm{~K},(\mathrm{U}, \mathrm{Zr}$ )C+graphite composite fuel fractures at $\sim 50 \mathrm{MPa}[1]$, but permanently deforms above. Uranium dioxide and tungsten show similar behavior. The work of Griffith [24] and Irwin [25] provide a theoretical basis for crack propagation being impeded with the onset of plasticity at higher temperatures.

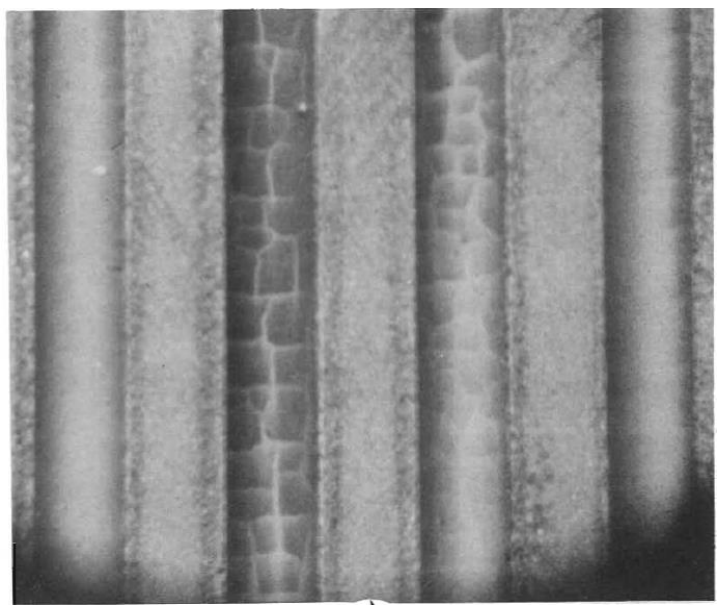

$1700 \mathrm{~K}$

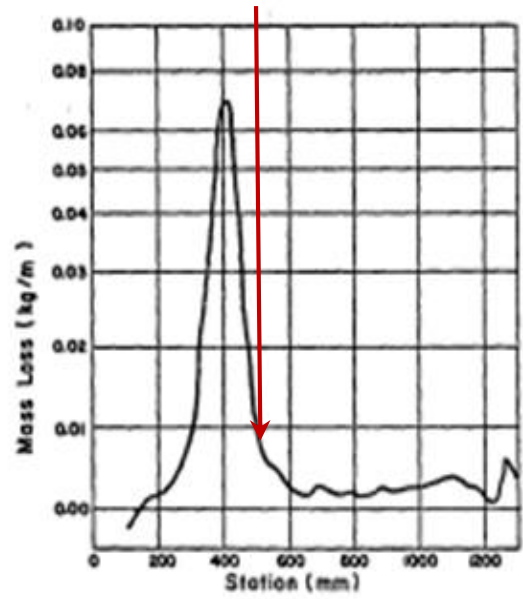

Figure 10. Mid-passage erosion region of graphite-composite fuel element (left), and mass loss versus length for $(\mathbf{U}, \mathbf{Z r}) \mathbf{C}$-graphite fuel element in NF-1 test (right). NERVA fuel element interior coolant channels experienced coating cracks in the NF-1 test, while edge channels retained their coatings. From Ref. [1].

1. What happens to cracks in NTP graphite-composite fuel elements?

The temperature increases along NTP fuel elements, so all temperatures (10-2900 K) are present. A brittle region is expected at the cold end of the fuel element, while the hot end should be crack free, but permanent deformation (dimensional instability) is possible. In graphite-composite fuel elements with $\mathrm{ZrC}$ coatings below 1500 $\mathrm{K}$, the coating will be in tension and cracking is possible; above $1500 \mathrm{~K}$ cracking should be reduced. Figure 10 shows the cracking behavior of a graphite-composite fuel element from NF-1. For this fuel element, ZrC coating

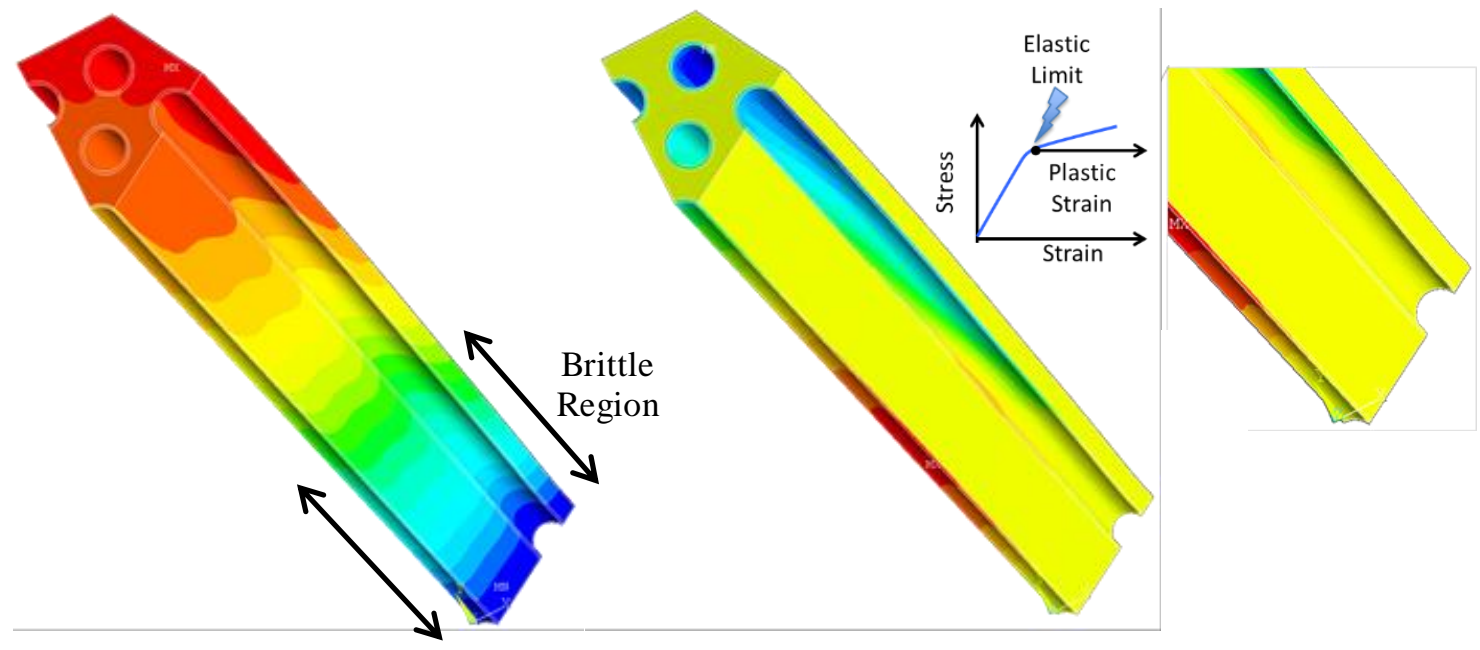

Figure 11. NERVA (U, Zr)C-graphite composite fuel element simulated in NF-1 reactor (no tie tube); temperature (left) and axial component of plastic strain (right). A brittle region for ZrC would be expected at the cool end where temperatures are below $1500 \mathrm{~K}$. Note that axial plastic strain decreases toward inlet for interior coolant channel as shown in the inset. 
cracking and fuel loss is limited to a region just below $1700 \mathrm{~K}$. Over many fuel elements tested, the trend is for cracks to occur in a "mid-passage region".

In an effort to duplicate this behavior, simulations [26] were conducted for a full length fuel element with the NF-1 geometry which has no tie tubes, as shown in Figure 11. "Best effort" elastic-plastic, temperature-dependent mechanical properties were specified in the ANSYS fluid/thermal/structural simulation. The inset in Figure 11 shows both the elastic and plastic regions of the stress-strain curve. How is cracking predicted in the model? Where the stress analysis shows large plastic deformation (red) in the cool, brittle region ( $\mathrm{T}<1500 \mathrm{~K}$ ) cracking is expected, while in the hotter regions, plastic deformation and no cracking is predicted. The region of cracking in Figure 11 is very consistent with the mid-passage erosion shown in Figure 10. Only the interior channel shows plastic deformation and cracking, and the strong plastic deformation (red region) and cracking region is a narrow band in the mid-passion region. The brittle end shows no cracking.

\section{What happens to cracks in NTP cermet fuel elements?}

Again, a brittle region is expected at the cold end of the fuel element. However, the CTE mismatch puts W and $\mathrm{W} 125 \%$ Re coatings into compression in this cold, brittle region with a risk of buckling and blistering of the coating - which has been observed [20]. In the absence of experimental data, this analysis only indicates behavior to look for; a prediction about the degree of blistering of cermet coatings is difficult. Fabrication is likely to be influential. Cycling cermet fuel samples to high temperatures completely misses any brittle behavior.

\section{Fluid/Thermal/Structural+Neutronic Analysis of Fuel Elements}

Beyond materials and stress issues, there are fluid and heat transfer issues for NTP fuel elements. Fluid/thermal/structural + neutronic simulations [15] of the SNRE fuel element have been performed to understand heat transfer issues. At $4.6 \mathrm{MW}_{\mathrm{t}} / \mathrm{L}$ peak heat deposition, the design is not as extreme as cermet designs. Predictions of fuel maximum temperature, temperature distribution, heat transfer to the tie tube, and pressure drops agree with legacy analyses, and suggest a mature design. Figure 12 shows temperature distributions through the fuel element and propellant at operating conditions.
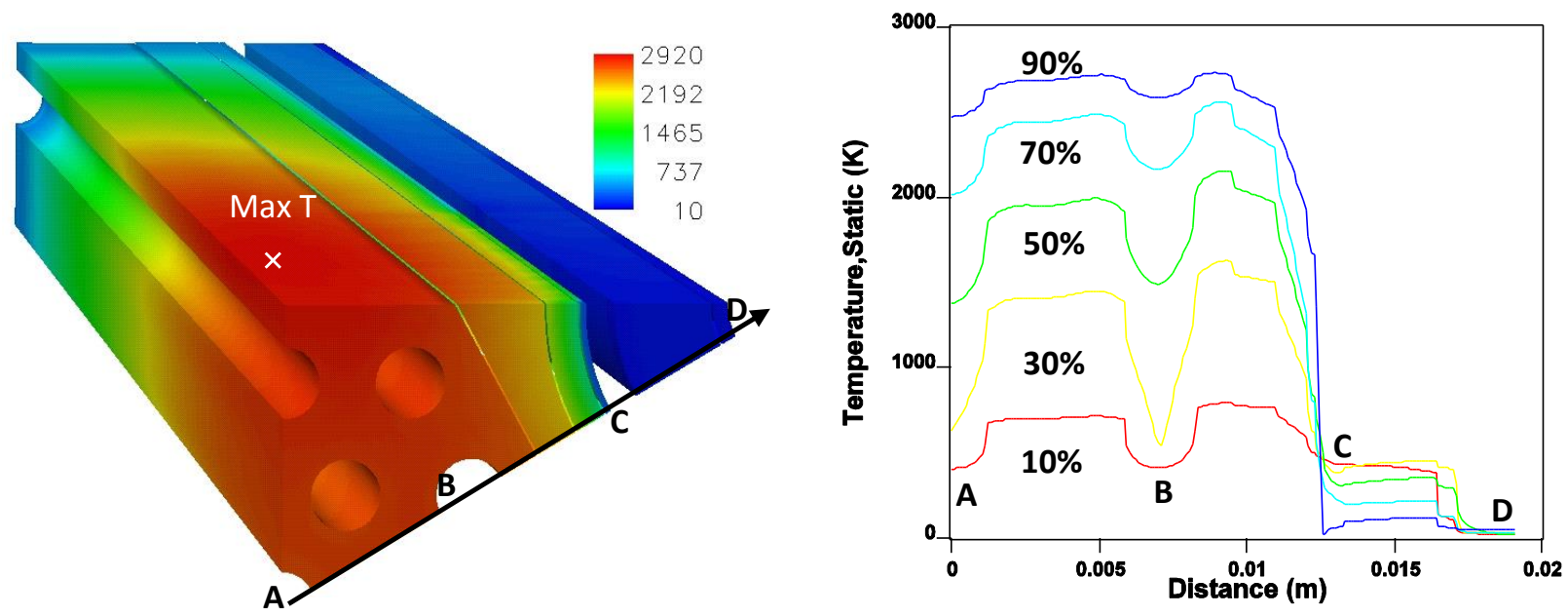

Figure 12. Predicted temperature distribution $(K)$ through graphite-composite fuel element and tie tube symmetric sector. Graph (right) shows temperature on path ABCD at 10,30, 50, 70, and 90\% axial stations from cold end to hot end. From Ref. [15].

With higher peak heat deposition rates (Figure 6), the cermet fuel elements have a more demanding design, that is, more heat must be transferred to the propellant/coolant per unit volume. ANL 200 reactor design had a performance goal of $2770 \mathrm{~K}$ peak fuel temperature, but the terminal report [5] shows a peak centerline fuel temperature of $3000 \mathrm{~K}$ at a max heat deposition of $5.16 \mathrm{MW}_{\mathrm{t}} / \mathrm{L}$. Simulations [18] of the ANL 200 fuel element are consistent with this higher temperature (Figure 13). The GE 710 fuel element was also simulated, and it showed very high pressure drops through the coolant tubes. Consequently, the coolant tube diameters were increased in the GE 711 design. Figure 6 and Figure 7 suggest that the GE 711 design has lower temperature drop across the fuel element cross section, and this has favorable consequences for thermal stress in the fuel element. 

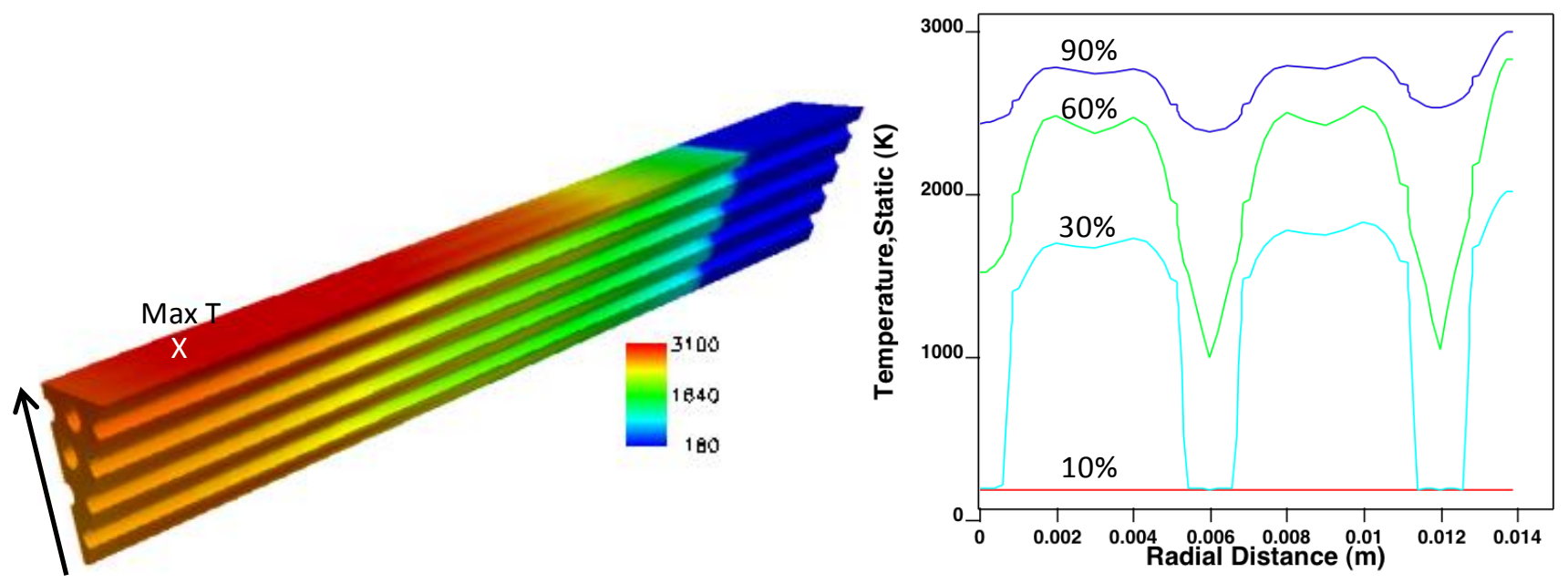

Figure 13. Temperature distribution (K) for ANL 200 cermet fuel element (left) and graph (right) of radial variation from center to edge through two and a half coolant channels. The location of maximum temperature is marked at left. Radial distance is from fuel element center to edge as marked by the arrow. From Ref. [18].

\section{Conclusion}

Predicting which fuel element type, graphite-composite or cermet, will eventually lead to the best rocket/reactor is not trivial - some design issues remain unknown until after prototypes are tested. With 23 rocket/reactor tests and thousands of fuel elements fabricated and tested, graphite-based fuels have a substantial legacy, yet coating cracking issues are understood, but not resolved. Further, water immersion criticality must be addressed and will add design complexity. The best cermet fuel samples had good thermal cycling performance up to $2770 \mathrm{~K}$, but the fuel degrades quickly at temperatures $200 \mathrm{~K}$ higher. The brittle behavior (blistering) of $\mathrm{W}$ or $\mathrm{W} \backslash 25 \%$ Re cermet matrix and cladding may be an advantage. The relatively large amount of highly-enriched uranium needed in cermet reactors is an issue. The authors are concerned that cermet fuel fabrication will be more costly and complex than legacy graphite-composite fuel fabrication methods. NASA's "leader-follower" fuel decision is prudent with the selection of graphite-composite fuel as the lead fuel while materials research and fabrication testing needs to continue with cermet fuel.

\section{Acknowledgments}

The authors express thanks to Chris Moore and John Warren at NASA Headquarters who supported this work through the Nuclear Thermal Propulsion project established as part of the Advanced Exploration Systems Program. The authors also thank Stan Borowski for his guidance and support, and Raj Sai, Jim Fittje, Charles Sarmiento, and Tom Lavelle for many helpful discussions. The GRC library staff tirelessly located many documents, journal articles, and reports.

\section{References}

[1] L. L. Lyon, "Performance of (U, Zr)C-Graphite (Composite) and of (U, Zr)C (Carbide) Fuel Elements in the Nuclear Furnace 1 Test Reactor," LA-5398-MS, Los Alamos Scientific Laboratory, Los Alamos, 1973.

[2] General Electric, Nuclear Materials and Propulsion Operation, "710 High-Temperature Gas Reactor Program Summary Report; Volumes I-VI," GEMP-600, Vol 1 to 6, 1968.

[3] D. R. Koenig, "Experience Gained from the Space Nuclear Rocket Program (Rover)," LA-10062-H, Los Alamos National Lab., Los Alamos, NM, May 1986.

[4] J. M. Taub, "A Review of Fuel Element Development for Nuclear Rocket Engines," Los Alamos National Lab., LA-5931, Los Alamos, NM, June 1975.

[5] Argonne National Laboratory, "Nuclear Rocket Program Terminal Report," ANL-7236, Argonne, IL, 1968.

[6] S. J. Kaufman, "Feasibility Study of a Tungsten Water-Moderated Nuclear Rocket, I Summary Report," NASA TM X-1420, 1968. 
[7] R. E. Rom, "Review of Nuclear Rocket Research at NASA's Lewis Research Center from 1953 thru 1973," in AIAA/NASA/OAI Conference on Advanced SEI Technologies, AIAA 91-3500, 1991.

[8] C. Haertling and R. J. Hanrahan, "Literature Review of Thermal and Radiation Performance Parameters for HighTemperature, Uranium Dioxide Fueled Cermet Materials," Journal of Nuclear Materials, vol. 366, pp. 317-335, 2007.

[9] L. B. Lundberg and R. R. Hobbins, "Nuclear Fuel for Very High Temperature Applications," in Intersociety Energy Conversion Engineering Conference, San Diego, 1992.

[10] J. S. Anderson, J. O. Sawyer, H. W. Worner, G. M. Willis and M. J. Bannister, "Decomposition of Uranium Dioxide at its Melting Point," Nature, vol. 185, no. 915-916, pp. 228-229, March 26, 1960.

[11] R. J. Beals, J. H. Handwerk and B. J. Wrona, "Behavior of Urania-Rare-Earth Oxides at High Temperatures," Journal of the American Ceramic Society, vol. 52, no. 11, pp. 578-581, Nov. 1969.

[12] R. J. Baker, J. L. Daniel, W. J. Lackey, R. J. S. F. A. Lobsinger, E. A. Snajdr and W. E. Roake, "Basic Behavior and Property of W-UO2 Cermets," NASA CR-54840, Nov. 1965.

[13] M. E. M. Stewart, "A Historical Review of Cermet Fuel Developmet and the Engine Performance Implications," in Nuclear and Emerging Technologies for Space-NETS 2015, Albuquerque, 2015.

[14] B. G. Schnitzler and S. Borowski, "Neutronics Models and Analysis of the Small Nuclear Rocket Engine (SNRE)," in 43rd AIAA Joint Propulsion Conference, Cincinnati, July, 2009.

[15] M. E. M. Stewart and B. G. Schnitzler, "Thermal Hydraulics and Structural Analysis of the Small Nuclear Rocket Engine (SNRE) Core," in 43rd Joint Propulsion Conference, AIAA 2007-5619, Cincinnati, July 2007.

[16] T. Leonhardt, "Properties of Tungsten-Rhenium and Tungsten-Rhenium with Halfnium Carbide," JOM; The Journal of the Minerals, Metals \& Materials Society, vol. 61, no. 7, pp. 68-71, 2009.

[17] P. L. Raffo, "Yielding and Fracture in Tungsten and Tungsten-Rhenium Alloys," NASA TN D-4567, May 1968.

[18] M. E. M. Stewart and B. G. Schnitzler, "Thermal, Fluid, and Structural Analysis of a Cermet Fuel Element," in 48th Joint Propulsion Conference, AIAA 2012-3959, Atlanta GA, August 2012.

[19] ANSYS, "ANSYS Multiphysics Software, Ver. 10.0," ANSYS Inc., Cannonsburg, PA, 2006.

[20] Argonne National Laboratory, "Nuclear Rocket Program Quarterly Progress Report, Fourth Quarter 1965," ANL-7150, Argonne, IL, 1965.

[21] D. W. Lee and J. S. Haggerty, "Plasticity and Creep in Single Crystals of Zirconium Carbide," Journal of the American Ceramic Society, vol. 52, no. 12, pp. 641-647, Dec 1969.

[22] R. Darolia and T. F. Archbold, "Plastic deformation of polycrystalline zirconium carbide," Journal of Materials Science, vol. 11, pp. 283-290, 1976.

[23] J. F. Bryon, "Yield and Flow of Polycrystalline Uranium Dioxide," Journal of Nuclear Materials, vol. 27, no. 1, pp. 48-53, 1968.

[24] A. A. Griffith, "The Phenomena of Rupture and Flow in Solids," Philosophical transactions of the royal society of london, Series A, vol. 221, pp. 163-198, 1921.

[25] G. R. Irwin, "Analysis of Stresses and Strains Near the End of a Crack Traversing a Plate," Journal of Applied Mechanics, pp. 361-364, 1957.

[26] M. E. M. Stewart and B. G. Schnitzler, "A Comparison of Materials Issues for Cermet and Graphite-Based NTP Fuels," in 49th AIAA Joint Propulsion Conference, AIAA 2013-3999, San Jose, CA, 2013.

[27] A. F. Lietzke, N. T. Saunders, G. K. Watson, R. E. Gluyas and J. G. Slaby, "Fuel Elements and Fuel-Element Materials," NASA X66-51413, 1966. 